\title{
HIGH PERFORMANCE LIQUID CHROMATOGRAPHY OF FREE CATECHOLAMINES IN URINE USING 1,2-DIPHENYLETHYLENEDIAMINE AS NEW PRECOLUMN FLUORESCENT DERIVATIZATION REAGENT
}

\author{
Hitoshi NOHTA, Akane MITSUI, and Yosuke OHKURA ${ }^{\circledR}$ \\ Faculty of Pharmaceutical Sciences, Kyushu University 62, \\ Maidashi, Higashi-ku, Fukuoka-shi 812, Japan
}

\begin{abstract}
A simple, rapid and highly sensitive method for the determination of free catecholamines(norepinephrine, epinephrine and dopamine) in urine is described which employs high performance liquid chromatography with fluorescence detection. Catecholamines and isoproterenol added as an internal standard in $100 \mu \mathrm{l}$ of urine, after chromatography on a small column of CM-Sephadex $\mathrm{C25}$, are converted into the corresponding fluorescent compounds by the reaction with 1,2-diphenylethylenediamine in aqueous ethanol. These compounds are separated within $7 \mathrm{~min}$ on a reversed phase column, TSK-gel ODS-120T, with isocratic elution using aqueous dioxane containing a Tris hydrochloric acid buffer (pH 7.0). The detection limits of norepinephrine, epinephrine and dopamine are 20, 30 and $40 \mathrm{fmol}$ in a $50 \mu \mathrm{l}$ injection volume, respectively.
\end{abstract}

Many methods using high performance liquid chromatography (HPLC) coupled with fluorescence detection have been introduced to the determination of catecholamines (CAs) in biological materials. They are classified into two types, post column derivatization methods such as trihydroxyindole(THI) ${ }^{1)}{ }^{2}$ and ethylenediamine condensation $^{3)}$ methods, and pre column derivatization methods using fluorogenic reagents for amines, fluorescamine ${ }^{4)}$, o-phthalaldehyde ${ }^{5)}$ and Dansyl chloride ${ }^{6)}$. Though the THI methods have most widely been used because of their high sensitivity to l-norepinephrine (NE) and 1-epinephrine(E), the sensitivity is not high enough to determine dopamine(DA) at low concentrations. The pre column derivatization methods are not generally very sensitive, and the derivatization reaction is not selective for CAs and so require rather complicated clean up procedures for biological samples.

In the previous paper, we reported that 1,2-diphenylethylenediamime(DPE) reacted sensitively and selectively with catechol compounds in neutral medium in the presence of potassium ferricyanide at ambient temperature to give fluorescent compounds and that this reaction was accelerated by glycine, and thus a fluorimetric method was established for the determination of $\mathrm{CAs}^{7)}$. The reaction mixture with DA in this method, however, gives two peaks in the chromatogram when subjected to a reversed phase HPLC. Therefore, this reaction cannot be successfully 
applied to pre column derivatization of CAs .

Recently, we have found that water miscible organic solvent such as ethanol accelerates the reaction of DPE with CAs, and the reaction mixture gives single peaks for individual $\mathrm{CAs}$ and dl-isoproterenol(IP) in a reversed phase HPLC.

This study aims to apply the above findings to the pre column derivatization of CAs and to establish the conditions of rapid separation of their DPE derivatives by HPLC. We also describe the application of this method to the determination of free CAs in urine of normal human, using IP as an internal standard.

\section{EXPERIMENTAL}

Reagents and solutions

NE bitartrate and DA hydrochloride were purchased from wako Pure Chemicals (Osaka, Japan). IP hydrochloride and $\mathrm{E}$ bitartrate were obtained from Nakarai Chemicals(Kyoto, Japan) and Sigma Chemicals(St. Louis, U.S.A.), respectively. All other chemicals were of reagent grade. Deionized and distilled water was used. DPE was synthesized as described previously ${ }^{7)}$. Distilled ethanol was used. DPE solution(0.1 M; apparent $\mathrm{pH}, 7.0)$ was prepared by dissolving $212 \mathrm{mg}$ of DPE in $10 \mathrm{ml}$ of ethanol $-0.25 \mathrm{M}$ hydrochloric acid(6:4, v/v). CM-Sephadex C25 (Pharmacia Japan, Tokyo, Japan) column was prepared by packing $0.2 \mathrm{ml}$ of the ion exchanger to a glass tube (130 mm $\times 4 \mathrm{~mm}$ I.D.) in the usual manner. The column was washed successively with $2 \mathrm{ml}$ of $0.1 \mathrm{M}$ sodium hydroxide(once), $2 \mathrm{ml}$ of $2 \mathrm{M}$ sodium chloride(twice), $2 \mathrm{ml}$ of water(three times) and finally $2 \mathrm{ml}$ of $0.2 \mathrm{M}$ phosphate buffer(pH 6.2) (three times). The used column can be regenerated by washing in the same way and is usable more than ten times. Urine $(24 \mathrm{~h})$ was collected in the presence of $6 \mathrm{M}$ hydrochloric acid $(10 \mathrm{ml})$, stored at $4^{\circ} \mathrm{C}$ and used within 2 weeks.

Apparatus

A TSK-gel ODS-120T column $(250 \mathrm{~mm} \times 4.6 \mathrm{~mm}$ I.D., Toyo Soda, Tokyo, Japan $)$ was used. A Beckman 112 solvent delivary module was used, equipped with a Rheodyne 7125 syringe-loading sample injector valve $(50 \mu 1$ loop) and a Gilson Spectra/gro filter fluorometer fitted with a $45 \mu \mathrm{l}$ flow cell and 7-60X excitation and 3-72M emission filters. Uncorrected fluorescence excitation and emission spectra of the eluate were measured with a Hitachi 850 fluorescence spectrophotometer fitted with a $20 \mu \mathrm{l}$ flow cell setting the spectral bandwidths of $5 \mathrm{~nm}$ in both the excitation and emission monochromators. Temperature of the HPLC column was controlled by using a Toyo Soda HLC-805 column oven.

Procedure for the fluorescent derivatization and HPLC (Procedure A)

To $0.8 \mathrm{ml}$ of a sample solution, $1.2 \mathrm{ml}$ of ethanol, and $0.1 \mathrm{ml}$ each of the DPE solution and $15 \mathrm{mM}$ potassium ferricyanide solution were successively added. The mixture was allowed to stand at $37^{\circ} \mathrm{C}$ for $30 \mathrm{~min}$ or longer to develop the fluorescence. A $50 \mu 1$ portion of the mixture was injected into the chromatograph. The mobile phase was a mixture of dioxane and $50 \mathrm{mM}$ Tris hydrochloric acid buffer(pH $7.0)(3: 2, \mathrm{v} / \mathrm{v})$. The flow rate was $1.0 \mathrm{ml} / \mathrm{min}$. The column temperature was $50^{\circ} \mathrm{C}$. 
Procedure for the determination of urinary CAs (Procedure $B$ )

To $100 \mu \mathrm{l}$ of a urine sample, $100 \mu \mathrm{l}$ of $1 \mathrm{nmol} / \mathrm{ml}$ IP solution and $1 \mathrm{ml}$ of $0.2 \mathrm{M}$ phosphate buffer ( $\mathrm{pH}$ 6.2) were added. An aliquot of the mixture ( $1 \mathrm{ml}$ ) was poured on to the CM-Sephadex C25 column. The column was washed three times with $1 \mathrm{ml}$ of water, and the adsorbed amines were eluted with $0.8 \mathrm{ml}$ of $2.0 \mathrm{M}$ sodium chloride. The eluate $(0.8 \mathrm{ml})$ was treated by the procedure $A$. The amount of CAs were calculated based on an internal standard method. For calibration of the ratios of the peak heights due to individual CAs to that due to IP, $100 \mu 1$ of urine sample was replaced with $100 \mu l$ of a standard solution of CAs( $1 \mathrm{nmol} / \mathrm{ml}$ each) and the same procedure was carried out.

\section{RESULTS AND DISCUSSION}

HPLC conditions

Figure 1 shows the chromatograms obtained with a standard solution of CAs and IP, and with water for reagent blank. The DPE derivatives of these amines can be completely separated within 7 min(Table 1). The DPE derivatives in the eluates show the fluorescence excitation and emission maxima around 355 and $470 \mathrm{~nm}$, respectively (Table 1).

Aqueous organic solvents, methanol, ethanol, acetonitrile, tetrahydrofuran, dioxane, and their mixtures, were examined as mobile phase for reversed phase HPLC on TSK-gel ODS120T. The peaks for $E$ and DA can be most successfully separated when aqueous dioxane is used. The concentrations of dioxane in the mobile phase affect the retention times of the peaks(Fig. 2). With higher concentrations of dioxane, the peaks of the DPE derivatives shift to shorter retention times; $60 \%$ was selected for their rapid separation. Dioxane is very viscous and so the column should be kept at high temperature to reduce the column pressure and to obtain adequate retention times of the peaks. A temperature of $50^{\circ} \mathrm{C}$ was employed tentatively (the column pressure was $140 \mathrm{~kg} / \mathrm{cm}^{2}$ ).

The pHs(6.0-8.0) and the concentrations(10-100 mM) of Tris hydrochloric acid buffer have no effect on the retention times and heights of the peaks; $50 \mathrm{mM}$ Tris hydrochloric acid buffer of $\mathrm{pH} 7.0$ was employed in the procedure. The Tris hydrochloric acid buffer can be replaced with water, but the peaks slightlybroaden. The detection limits for the compounds in a standard mixture were $10 \mathrm{fmol}$ each for NE and IP, and $15 \mathrm{fmol}$ each for $E$ and $D A$ per $50 \mu l$ of injection volume.

Derivatization

Water miscible organic solvents, methanol, ethanol, acetonitrile, dioxane, 
Table 1 Retention times, fluorescence excitation and emission maxima and relative peak heights of the DPE derivatives of catechol compounds

\begin{tabular}{lcccc}
\hline Compound & $\begin{array}{c}\text { Retention time/ } \\
\text { min }\end{array}$ & $\begin{array}{c}\text { Excitation } \\
\text { maximum } \\
\text { nm }\end{array}$ & $\begin{array}{c}\text { Emission } \\
\text { maximum } \\
\text { nm }\end{array}$ & $\begin{array}{c}\text { Relative } \\
\text { peak } \\
\text { height }\end{array}$ \\
\hline $\mathrm{NE}$ & 3.8 & 350 & 468 & 100 \\
$\mathrm{E}$ & 4.8 & 360 & 470 & 65 \\
$\mathrm{DA}$ & 5.5 & 350 & 480 & 63 \\
$\mathrm{IP}$ & 6.5 & 354 & 475 & 96 \\
1-DOPA & 4.6 & 344 & 482 & 32 \\
3,4-Dihydroxybenzyl- & 3.2 & 336 & 448 & 70 \\
$\begin{array}{l}\text { amine } \\
\text { 3,4-Dihydroxyphenyl- }\end{array}$ & 3.6 & 337 & 454 & 51 \\
ethyleneglycol & & & 450 & 24 \\
3,4-Dihydroxyphenyl- & 3.3 & 343 & & \\
acetic acid & & & & \\
\hline
\end{tabular}

Portions $(0.8 \mathrm{ml})$ of $1 \mathrm{nmol} / \mathrm{ml}$ solutions of catechol compounds were treated according to the procedure A. a, The peak height of DPE derivatives from $\mathrm{NE}$ was taken as 100.

2-methoxyethanol and acetone, accelerate the derivatization reaction. Of these solvents, ethanol and acetonitrile are most effective; ethanol was selected in the standard procedure for convenience. Maximum and constant peak heights are attained at ethanol concentrations in the reaction mixture in a range of 50 to $70 \%(\mathrm{v} / \mathrm{v})$ for $\mathrm{NE}, \mathrm{E}$ and $\mathrm{IP}$, and in a range of 60 to $70 \%(\mathrm{v} / \mathrm{v})$ for $\mathrm{DA}(\mathrm{Fig} .3)$; ethanol concentration of approximately $60 \%(\mathrm{v} / \mathrm{v})$ was selected as optimum. Figure 4 shows the effect of reaction time at $37^{\circ} \mathrm{C}$ on the peak heights for CAs and IP. The peak heights reach maximum and constant values after standing for $30 \mathrm{~min}$ or longer. Other conditions of the derivatization are optimum ${ }^{7)}$. The DPE derivatives in the reaction mixture were stable for at least $8 \mathrm{~h}$ even in daylight.

Determination of CAs in urine Urine contains various catechol compounds other than CAs which are mainly metabolites of CAs, such as 3,4-dihydroxyphenylethyleneglycol and

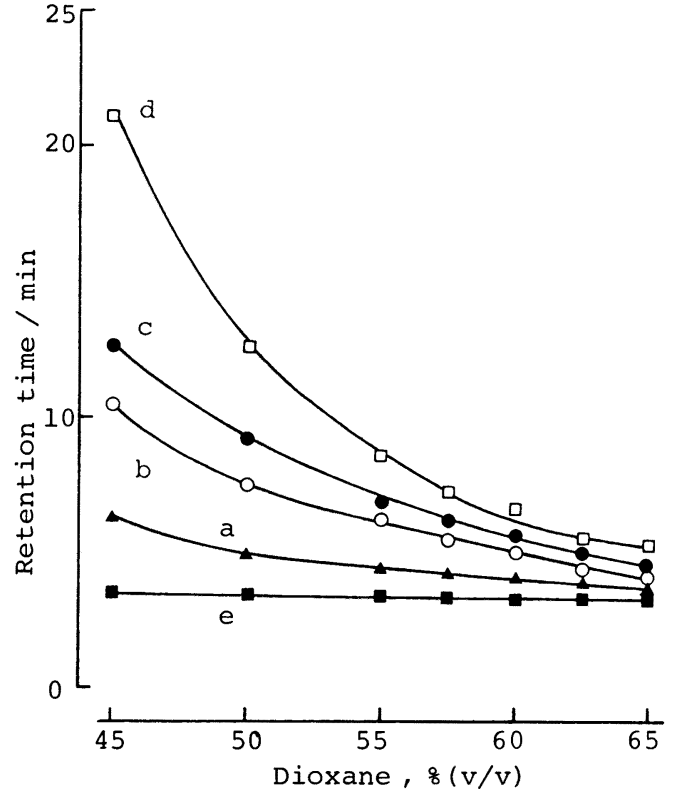

Fig. 2 Effect of the concentration of dioxane in the mobile phase on the retention times of DPE derivatives of CAs and IP

Concentrations of CAs and IP: $0.1 \mathrm{nmol} /$ ml each Curves: $a$; NE, b; E, c; DA, d; IP, e; reagent blank 


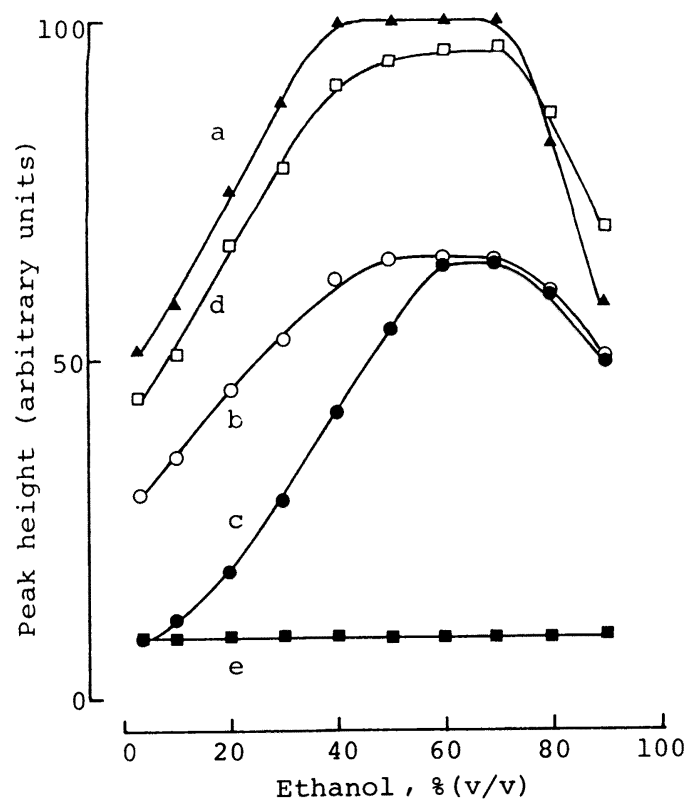

Fig. 3 Effect of the concentration of ethanol in the derivatization reaction on the peak height

Concentrations of $\mathrm{CAs}$ and IP: $0.1 \mathrm{nmol} /$ $\mathrm{ml}$ each Curves: $a$; $\mathrm{NE}, \mathrm{b} ; \mathrm{E}, \mathrm{c} ; \mathrm{DA}$, d; IP, e; reagent blank

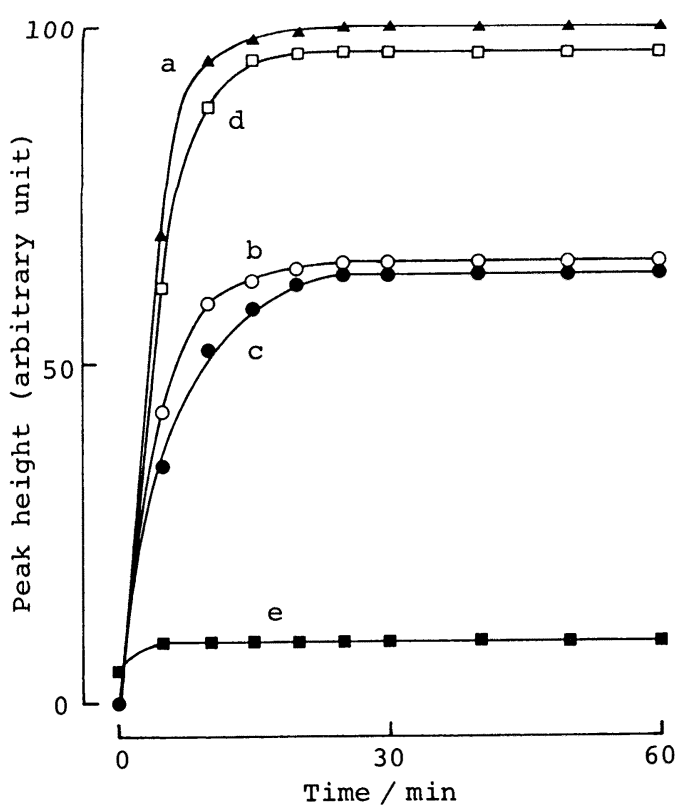

Fig. 4 Effect of standing time at $37^{\circ} \mathrm{C}$ on the peak height

Concentrations of CAs and IP: $0.1 \mathrm{nmol} /$ $\mathrm{ml}$ each Curves: $a$; $N E, b ; E, C ; D A$, d; IP, e; reagent blank

3,4-dihydroxyphenylacetic acid ${ }^{8}$. They react with DPE to afford fluorescent compounds(Table 1) and interfere with the assay of CAs if they present in urine at high concentrations. For the removal of these compounds from urine sample, chromatography on small columns of strongly acidic cation exchanger(Dowex $50 \mathrm{~W} \times 8$ ) and weakly acidic cation exchangers(CM-Sephadex C25, Amberlite CG50 Type I and Dowex CCR2) were tested. A clean up technique using acid-treated alumina ${ }^{9)}$ was also examined. A CM-Sephadex C25 column gave most reproducible recoveries of CAs and IP; the recoveries of $0.1 \mathrm{nmol}$ each of the amines applied on to the column as $1.0 \mathrm{ml}$ of their solution in $0.2 \mathrm{M}$ phosphate buffer $(\mathrm{pH} 6.2)$ were $71.7 \pm 1.5$ for $\mathrm{NE}, 61.5 \pm 2.4$ for $\mathrm{E}, 63.7 \pm 1.1$ for $\mathrm{DA}$ and $57.9 \pm 2.2$ for $\mathrm{IP}$ (mean \pm standard deviation(S.D.), $n=12$ each). The compounds having no amino group and 1-DOPA in urine sample were completely removed by this chromatography.

Sodium chloride solution as eluent of CAs and IP in the chromatography on the Sephadex column has an effect on the peak heights especially for DA. Sodium chloride at a concentration of approximately $1.5 \mathrm{M}$ in the eluate reduced the peak height for DA to $55 \%$ and those for NE, E and IP to $95 \%$ of those obtained with CAs and IP dissolved in water, respectively. This is large enough to measure DA because the amine occurs at high concentrations in urine.

Figure 5 shows a typical chromatogram obtained with a normal human urine. 
Peaks for CAs and IP are successfully separated under the conditions of HPLC. The components of peaks 2-4 were identified on the basis of the retention times and fluorescence excitation and emission spectra of the eluates by comparison with a standard solution of CAs and also by co-chromatography of the standard and urine sample. The peak height for $D A$ is reduced by the presence of sodium chloride in the eluate for the reason described above. Peak 1 in the chromatogram has a retention time of $3.3 \mathrm{~min}$. The peak is due mainly to endogenous compound(s) in urine sample and partially to the reagent blank, and its eluate has fluorescence excitation and emission maxima at 340 and $450 \mathrm{~nm}$, respectively. This suggests that the peak component(s) may be some compound(s) with catechol and amino moieties, though the component(s) could not be identified. Peak 1 did not interfere with the determination of $\mathrm{NE}$ (peak 2) when the procedure $B$ was applied to 20 samples of normal urine, and so further clean up of the sample is not necessary.

Linear relationships were observed between the ratios of the peak heights of CAs to that of IP and the amounts of CAs added in the range of $0.01-1.0$ nmol each to $100 \mathrm{\mu l}$ of urine. The recoveries of $\mathrm{NE}, \mathrm{E}, \mathrm{DA}$ and IP added in the amounts of $0.1 \mathrm{nmol}$ each to $100 \mathrm{\mu l}$ of urine, were $69.8 \pm 4.9,64.5 \pm 2.5,62.7 \pm 4.1$ and $58.2 \pm 3.7 \%$ (mean \pm S.D., $n=6$ each). The limits of detection for $\mathrm{NE}, \mathrm{E}$ and $\mathrm{DA}$ in urine were $1.0,1.5$ and $2.0 \mathrm{pmol} / 0.1 \mathrm{ml}(20,30$ and $40 \mathrm{fmol} / 50 \mu l$ of injection volume), respectively, at a signal-to-noise ratio of 2 . The precision of the method was established with respect to repeatability by using an urine sample. The coefficients of variation for $\mathrm{NE}, \mathrm{E}$ and $\mathrm{DA}$ were $3.2,4.8$ and $3.0 \%$ at mean concentrations of $0.25,0.11$ and $2.57 \mathrm{nmol} / \mathrm{ml}$ urine, respectively.

The amounts of free CAs in $24 \mathrm{~h}$ urine from 20 healthy persons(22-53 years old) assayed by this method were $221.9 \pm 93.9 \mathrm{nmol}(37.6 \pm 15.9 \mu \mathrm{g})$ for $\mathrm{NE}, 83.9 \pm 51.9$ nmol $(16.4 \pm 9.5 \mu \mathrm{g})$ for $\mathrm{E}$ and $2.15 \pm 0.94 \mu \mathrm{mol}(329 \pm 144 \mu \mathrm{g})$ for DA (mean $\pm \mathrm{S} . \mathrm{D}$.$) .$ These values are in good agreement with data obtained by other workers ${ }^{10)}$.

This method is highly sensitive and rapid enough to assay 10 samples within $3 \mathrm{~h}$. The THI methods cannot determine DA at low concentrations and the pre column derivatization methods using fluorescamine or o-phthalaldehyde do not allow to determine $\mathrm{E}$, a secondary amine. The pre column derivatization method using Dansyl chloride is liable to form artifact and the Dansyl derivatives are unstable. 
The present method permits the assay of all the CAs simultaneously and does not require complicated clean up procedure compared with the HPLC with electrochemical detection 10)11). This method should be useful for biological and biomedical investigations of human diseases accompanying change in the level of urinary CAs.

We are grateful to Scientific Instrument Division of Toyo Soda Manufacturing Co. for generous gifts of HPLC columns.

\section{REFERENCES}

1) Y. Yui, T. Fujita, T. Yamamoto, Y. Itokawa, C. Kawai: Clin. Chem., 26, 194(1980).

2) A. Yamatodani, H. Wada: Clin. Chem., 27, 1983(1981).

3) T. Seki: J. Chromatogr., 155, 415(1978).

4) K. Imai, Z. Tamura: Clin. Chim. Acta, 85, l(1978).

5) L.D. Mell, A.R. Dasler, A.B. Gustafson: J. Liq. Chromatogr., 1, 261(1978).

6) R.W. Frei, M. Thomas, I. Frei: J. Liq. Chromatogr., 1, 443 (1978).

7) H. Nohta, A. Mitsui, Y. Ohkura: submitted for publication in Anal. Chim. Acta.

8) D.F. Sharman: British Medical Bulletin, 29, 110(1973).

9) A.H. Anton, D.F. Sayre: J. Pharmacol. Exp. Ther., 138, 369(1962).

10) T.P. Moyer, N.-S. Jiang, G.M. Tyce, S.G. Sheps: Clin. Chem., 25, 256(1979).

11) P.T. Kissinger, R.M. Riggin, R.L. Alcorn, L.D. Rau: Biochem. Med., 13, 299 (1975).

Keyword phrases

catecholamines in human urine; high performance liquid chromatography with fluorescence detection; pre column derivatization with 1,2-diphenylethylenediamine. 